\title{
Çözüm Ă̆ı Üretim Yöntemleri Ve Geliştirilen Program Kullanılarak Hareketli Çözüm Ağı Üretimi
}

\author{
Mehmet ÇINAR ${ }^{1 *}$ \\ ${ }^{1}$ Bitlis Eren Üniversitesi, Tatvan Meslek Yüksekokulu, Elektronik ve Otomasyon Bölümü, Bitlis
}

\begin{abstract}
Özet
Kısmi diferansiyel denklemlerin sayısal çözümünde en sık kullanılan yöntemlerden birisi sonlu elemanlar yöntemidir. Sonlu elemanlar yönteminde analiz yapılacak bölge sınırları belli olmak şartıyla çözüm bölgesi denilen alt bölümlere ayrıştırılır. Bu alt bölümlere ayrıştırma yöntemi çözülecek diferansiyel denklemin çeşidine göre değişmektedir. Çözüm bölgesini alt bölümlere ayrıştırabilmek için çeşitli çözüm ağı üretim teknikleri kullanılır. Uygun yöntem belirlenerek çözüm bölgesi alt bölmelere ayrıştırılarak çözümün daha hızlı ve doğru olması sağlanmaktadır. Klasik sonlu elemanlar yöntemi çözüm alanı üzerinde anlık analiz yapıldığında doğru sonuçlar vermektedir. Ancak zamana bağlı olarak kısmi diferansiyel denklemlerin değiştiği ve çözüm ağının da bölgesel olarak değiştiği durumlarda klasik sonlu elemanlar yöntemi yerine hareketli sonlu elemanlar yöntemi kullanılması faydalıdır. Hareketli sonlu eleman yöntemi kullanımı çözüm ağının sadece değişen bölgelerinde analiz yapılmasını sağlayarak hızlı bir şekilde sonuca gidilmesini temin eder. Bu çalışmada, iki boyutlu çözüm ağı üretim tekniklerinden bahsedilmiştir. Geliştirilen program yardımıyla çözüm ağı üzerindeki bölgesel değişikliklerin nasıl yapıldığı konuları detaylandırılmıştır. Uygulama olarak, C++ tabanlı bir yazılım gerçekleştirilmiştir.
\end{abstract}

Anahtar kelimeler: Çözüm Ağı Üretim Teknikleri, Sonlu Elemanlar Yöntemi, Hareketli Çözüm Ağı üretimi.

\section{Mesh Generation Techniques And Moving Mesh Generation By Using Developed Program}

\begin{abstract}
One of the most frequently used methods in the numerical solution of partial differential equations is the finite element method. In the finite element method, the region to be analyzed is separated into sub-regions called solution regions, provided that its boundaries are certain. The method of decomposing these subsections varies according to the type of the differential equation to be solved. Various mesh generation techniques are used to decompose the solution region into subsections. By determining the appropriate method, the solution region is divided into sub-divisions and the resolution is made faster and more accurate. The classic finite element method gives accurate results when instant analysis is performed on the solution area. However, it is useful to use the moving finite element method instead of the classical finite element method in cases where the partial differential equations change with time and the mesh changes regionally. The use of the moving finite element method ensures that only the analysis of the solution network is performed in the changing regions, resulting in a rapid result.In this work, two dimensional mesh generation techniques are mentioned. How the regional changes on the mesh are done with the help of the developed program is detailed. As an application, $\mathrm{C}++$ based software was implemented.
\end{abstract}

Keywords: Mesh Generation Techniques, Finite Element Method, Moving Mesh Generation.

*Sorumlu yazar: mcinar@beu.edu.tr

Geliş Tarihi: 20/09/2017 Kabul Tarihi: 29/09/2017 


\section{Giriş}

Fiziksel ortam ile çalışan çoğu bilim adamları iki önemli konu ile karşı karşıya kalır. Bunlar, fiziksel ortamın matematiksel formülasyonu ve diğeri de matematiksel modelin sayısal analizidir. Fiziksel ortamın matematiksel modelinin çıkarılması çoğu zaman temel matematik, fizik bilgisini gerektirir. Matematiksel formülasyondaki çoğu ifadeler sistemle ilgili diferansiyel denklem tipindedir. $\mathrm{Bu}$ diferansiyel denklemlerin çözümü, çalışılan fiziksel sistemin herhangi bir anda ki davranışı hakkında bilgi verir [1]. Çoğu problemler için ilgili denklemin türetilmesi zor değildir. Fakat bu denklemlerin tam çözümlerini elde etmek her zaman mümkün değildir. Bu durumda tam çözüm bulmak yerine yaklaşım yöntemleri kullanılarak, belirli bir hata ile çözüme gidilmeye çalışılır. Diferansiyel denklemin sonlu farklar yaklaşımında, sonraki türevler fark bölümleriyle temsil edilir. Böylece, verilen fiziksel ortamın sınır şartları zorlanarak, elde edilen cebrik denklem çözülür ve sonuç elde edilir.Varyasyonel yöntemler de ise, denklem, ağırlıklı integral şekline dönüştürülür ve daha sonra domen üzerinde yaklaşık çözümün doğrusal birleşimli olduğu kabul edilir [2]. Sonlu elemanlar yöntemi, geleneksel varyasyonal yöntemlerinin dezavantajlarının üstesinden gelir. Yöntem basit bir problem için aşağıdaki adımları kullanır:

\section{a) Verilen bölgenin sonlu eleman çözüm ağının oluşturulması:}

$\mathrm{Bu}$ adım sonlu eleman denklem formülasyonu bitirilene kadar bir gecikmeye sebep olabilir. Süreklilik problemlerinde alan değişkeni, çözüm bölgesindeki noktalara ilişkin bir fonksiyondur. Dolayısıyla alan değişkeninin sonsuz sayıda değerleri vardır ve problem sonsuz sayıda bilinmeyenlidir. Problemin sonlu sayıda bilinmeyenli duruma indirgenmesi amacıyla birinci adım olarak çözüm bölgesi sonlu sayıda eleman ile bölmelenir. Elemanlar üçgen, dörtgen, hexahedron, izoparametrik, vb. şekillerde ve değişik büyüklüklerde seçilebilir. Bu seçim, problemin tek, iki veya üç boyutlu olması durumu ve inceleme altındaki malzeme veya cihazın sınırları da göz önüne alınarak yapılır. Düzensiz şekillerde ve gelişi güzel bölümlendirmelerde üçgen elemanlar kolaylık sağlar. Bu elemanlar sınır yüzeylere kolaylıkla uyum sağlar. Böylece çözüm bölgesi, istenilen büyüklük ve sıklıkta elemanlar ile bölmelenerek dügüm sayısı ve dolayısıyla çözüm denklemlerinin sayısı değiştirilebilir. Bu elemanlarla bölmeleme yapıldıktan sonra elemanlara uygun düğüm numaraları ve eleman numaraları verilir [3].

\section{b) Çözüm ağı üzerindeki bütün eleman tipleri için şekil fonksiyonlarının türetilmesi:}

Her bir elemanı belirleyen adımlar yardımıyla o eleman üzerinde veya içinde alan değişkeninin değişimini gösteren şekil fonksiyonun tipi seçilir. Alan değişkeni skalar, vektörel veya yüksek dereceli bir tensör olabilir. Çoğu zaman alan değişkeni için polinomlar seçilir. Çünkü bunların integral ve türevlerini almak kolaydır. Polinomlar lineer, kuadratik, kübik,vb. yapıda olabilirler. Sisteme ait uygun sınır şartları belirlenir.

\section{c) Eleman özelliklerinin bulunması:}

Her bir elemanın özelliklerini tanımlayan matris eşitliklerinin bulunması, üçüncü adımı oluşturur. Bunun için kullanılan yaklaşımlardan bazıları; direk yaklaşım, varyasyonel yaklaşım, Ağırlıklı Artıklar yaklaşımı ve Enerji Dengesi Yaklaşımı şeklindedir.

\section{d) Eleman özelliklerinin birleştirilmesi:}

Tüm sistemi modelleyen özellikleri bulmak için elemanların ayrı ayrı olan özellikleri birleştirilir ve problemin sınır şartları sisteme yerleştirilerek sonuç denklem sistemi çözüme hazır hale getirilir.

\section{e) Denklem sisteminin çözümü:}

Tipik bağımlı değişken ;

$$
u=\sum_{i=1}^{n} u_{i} \psi_{i}
$$

olmak üzere, 
$\left[K^{e}\right]\left\{u^{e}\right\}=\left\{F^{e}\right\}$

şeklinde eleman denkleminin elde edilmesi. $K$ matrisi, ana matris olarak isimlendirilen matristir.

f) $\psi_{\mathrm{i}}$, eleman interpolasyon fonksiyon seçimi ve türetilmesi.

Dördüncü adımda elde edilen sonuç denklem sistemi, alan değişkeninin bilinmeyen değerlerini hesaplamak üzere çeşitli yöntemlerden yararlanarak çözülür. Eğer denklemler lineer ise; Gauss Elimination, Cholesky Decomposition gibi direk yöntemler veya Gauss Seidel, SOR (Successive Over Relaxion) gibi iteratif yöntemler kullanılabilir. Eğer denklemler nonlineer ise, bunların çözümünü elde etmek daha zordur ve Newton-Raphson gibi iteratif yöntemlerden yararlanılır.

\section{g) İstenen diğer hesaplamaların yapılması:}

Sisteme ait bazı önemli parametreleri hesaplamak için denklem sisteminin çözüm sonuçları kullanılabilir. Örnek olarak, elektrik alanlarının incelenmesini sağlayan Laplace denklemine ilişkin çözüm sonuçları sistemin potansiyel dağılımını verir. Eğer istenirse, düğümlerin potansiyel değerlerinden yararlanılarak alan şiddeti, depolanan enerji ve kapasite gibi hesaplamalar da yapılabilir [4].

Sonlu elemanlar yöntemiyle doğru ve güvenilir hesaplama yapabilmek için çözüm bölgesinin sonlu eleman çözüm ağının oluşturulması gerekir. Sonraki bölümde çözüm ağı üretim tekniklerinden bahsedilecektir.

\section{2. Çözüm Ağı Üretim Algoritmaları}

Bu bölümde, iki boyutta hem yüzey hem de hacim elemanı olarak, sonlu eleman çözüm ağı üretiminde kullanılan çözüm ağı üretim teknikleri açıklanmıştır. Bilindiği gibi çözüm ağının üretim sebebi analiz için veri hazırlamaktır. Bu kısımda sonlu eleman çözüm ağı üretiminde kullanılan uyarlamalı yapılar için de müsait olan çözüm ağı üretim tekniklerinden bahsedilecektir. Bu yöntemler aşağıdaki gibi sinıflandırılabilir [5]:

1. İki boyutlu üçgensel çözüm ağları.

a) İki boyutlu Delaunay ügenleme.

b) İlerleyen cephe yöntemi.

c) Yörünge çizgileri kullanarak çözüm ağ üretimi.

d) Alt bölmeleme yoluyla kenar bölme tekniği.

2. İki boyutlu dörtgensel çözüm ağları.

a) Doğrudan yöntemler.

b) Dolaylı yöntemler..

\section{1. İki Boyutlu Üçgensel Çözüm Ağları}

Bu bölümde üçgensel çözüm ağı üretiminde yaygın olarak kullanılan çözüm ağı üretim teknikleri hakkında bilgi verilecektir.

\subsection{1. İki Boyutlu Delaunay Üçgenleme}

En yaygın olarak kullanılan bir üçgenleme yöntemidir. Yöntem ilk defa Rus matematikçisi Boris Delaunay [6] tarafından 1934 yılında ortaya atılmıştır. Yöntemin kendisi doğrudan bir çözüm ağ1 üretimi için üçgen oluşturma olmayıp, varolan noktaların birleştirilmesi prensibine dayanır. Delaunay fikri uzun zamandır literatürde olmasına rağmen özellikle çözüm ağlarının üretiminde ilk olarak Lawson [7] tarafından kullanılmıştır. Aslında doğrudan bir üçgenleme yöntemi olmayıp kesişmeler olmayıncaya ve Delaunay şartı sağlanıncaya kadar sınırlarda üçgen üretme esasına dayanır. Delaunay şartı, birleştirilecek noktalardan iki boyutta en az bir tane üçgen oluşturacak şekilde ve oluşturulan üçgenin köşeleri bir çemberi elde edecek şekilde üçgenleme yapmaktır . Bunun için Voronoi 
diagramını oluşturacak şekilde noktaların dağglımı yapılmış olmalı ya da birleştirilecek noktalarda bu şart aranmalıdır. Şekil 1 yedi nokta için Voronoi ve Delaunay ayrıtlarını göstermektedir. Kesik çizgi ile gösterilen Voronoi ayrıtları ve sürekli çizgi ile gösterilenler ise Delaunay ayrıtlarıdır.
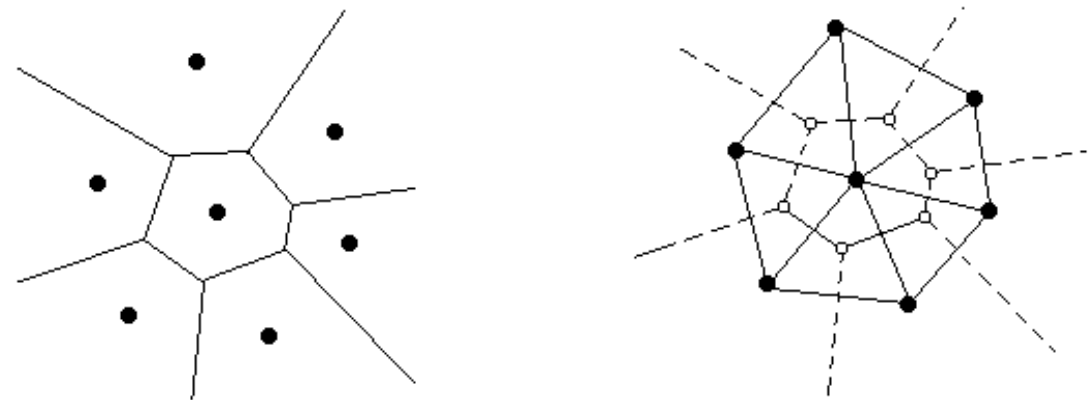

Şekil 1. Yedi nokta için Voronoi ve Delaunay ayrıtları

Şekil 2’ de Delaunay ve Delaunay olmayan iki üçgenleme yöntemi görülmektedir. Yöntem ilk şart olarak sınırlarda ayrık noktalar kullanmak suretiyle üçgenleme yapar. Sonradan araya eklenecek noktaların uygun yerleştirilip Delaunay şartını sağlaması istenir. Bu işlem için çeşitli teknikler önerilmiştir.

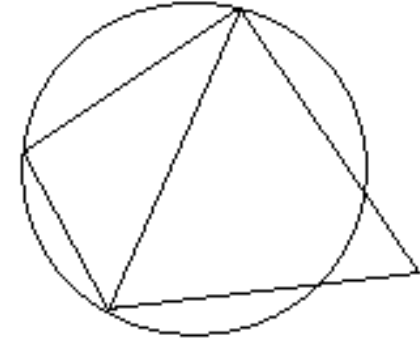

Şekil 2. a) Delaunay üçgenleme

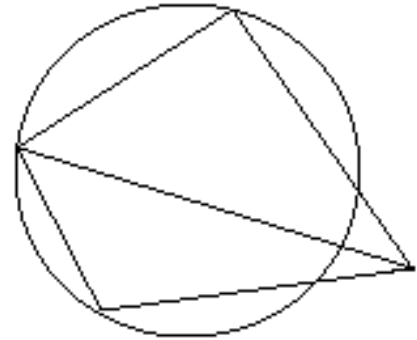

b) Delaunay olmayan üçgenleme

Sonlu eleman yaklaşımında, sınırda var olan üçgenlerin sınır bütünlüğünü koruması istenir. Bu durum gerçekleşmezse, o zaman verilen sınırlara göre tam olarak bir üçgenleme yapılmamış ve sonlu eleman analizdeki hata artmış olur .Bu durumda sonlu eleman analiz için veri hazırlanmamış olur. Bunu gidermek için çoğu zaman standart Delaunay üçgenleme yönteminden sonra bir düzeltme veya doğrulama işlemine gerek duyulur .Şekil 3’ de bu durum görülmektedir [8].

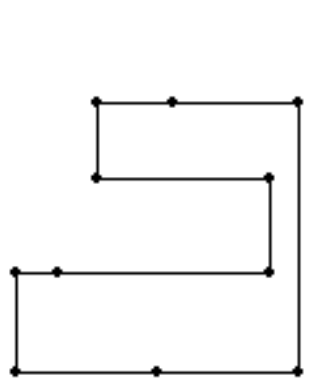

a )

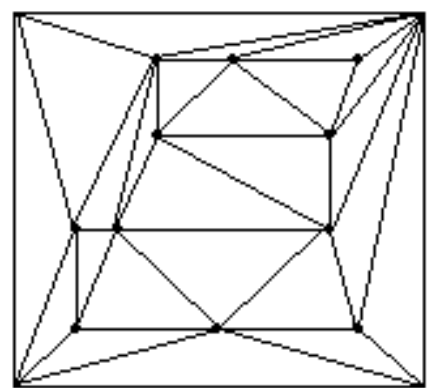

b )

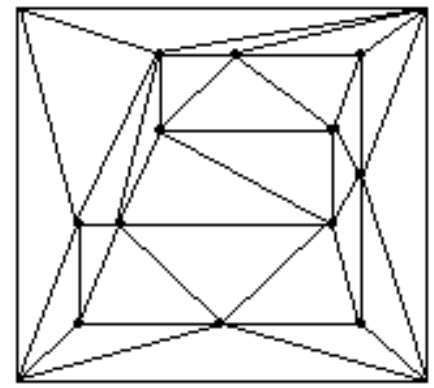

c)

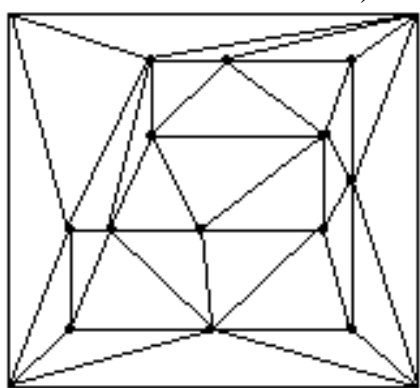

d )

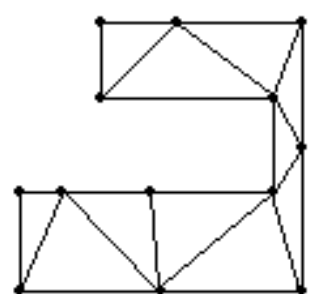

e )

Şekil 3. Sınır bütünlüğü korunmuş Delaunay üçgenleme adımları 
Şekil 3' deki adımlar kısaca aşağıdaki gibi açıklanabilir.

a) Sinırları tanımlayan noktalar.

b) Orijinal noktaların başlangıç Delaunay üçgenlemesi. Dikkat edilirse nesnenin dışında seçilen dört nokta içbükey bir ortam sağlar.

c) Kayı olan bir kenarın ortasına bir nokta eklenmesi.

d) Diğer ara noktanın eklenmesi.

e) Ortam dışındaki diğer bütün üçgenler atılarak sınır bütünlüğü sağlanacak şekilde Delaunay üçgenleme gerçekleştirilir.

Sınırlarda bu düzenlemelerin yapılmasının gerekmesi sınır zorlamalı Delaunay fikrinin ortaya çıkmasına sebep olmuştur. Sınır zorlamalı Delaunay üçgenleme işleminde yapılan Şekil 4' de görüleceği gibi sınır bütünlüğü köşeden köşeye noktaları yer değiştirme yoluyla yapılmaktadır.
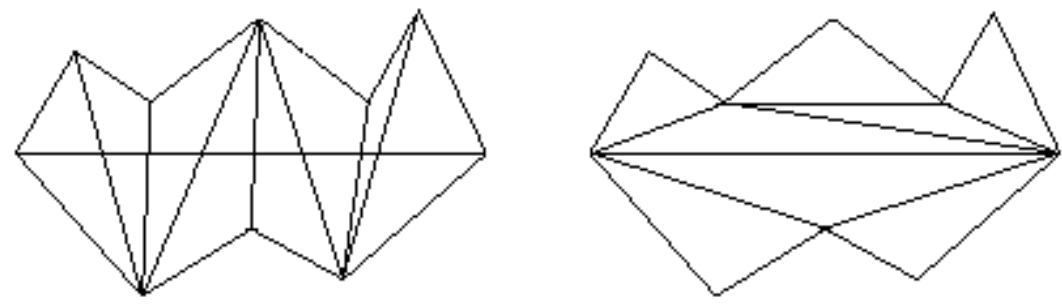

Şekil 4. Diagonal köşelerin birleştirilerek sınır zorlamalı Delaunay üçgenlemesi

Delaunay üçgenleme için izlenecek adımlar aşağıdaki gibidir.

1. Üçgenleme için kullanılacak noktaların içinde bulunacağı bir kapalı alan tanımlanması. Bu alanın özelliğinin içbükey olması işlemi kolaylaştırır. Ayrıca bu noktalar Voronoi diagramını tanımlayacak şekilde yerleştirilmesi.

2. Bu alan içine eklenecek olan herhangi bir noktanın bulunması.

3. Silinecek olan Voronoi diagramının bütün ayrıtlarının belirlenmesi.

4. Bütün silinmiş Voronoi ayrıtlarının bulunması. Bu noktalar yeni eklenecek noktaya bitişik noktalardır.

5. Yeni Voronoi ayritlarının eklenmesi.

6. Yeni komşu Voronoi ayrıtlarının eklenmesi ve gerekirse 5. Adıma gidip yeni Voronoi ayrıtlarının ilave edilmesi.

7. Yeni nokta eklenmesi için 2. ve 6. adıma geri gidilmesi.

\subsection{2. İlerleyen Cephe Yöntemi}

İlerleyen cephe yöntemi ilk olarak yapısal olmayan çözüm ağları üretimine uygulanmış daha sonraları ise Zhu [9] tarafindan bazı değişikliklerle dörtgenlere de uygulanmaya çalışılmıştır. Yöntemin genelleştirilmiş hali, üç boyutlu uzayda, yüzey üçgenleme uyarlamalı çözüm ağı üretimi, paralel üçgenleme vb. gibi alanlara uygulanmıştır .

İki boyutta ilerleyen cephe yöntemi ile üçgenleme işlemi aşağıdaki adımlardan ibarettir;

1. Sınırların ayrıklaştırılması.

2. Bu değerlerin listeye yerleştirilmesi.

3. Listenin, genel bir kriter olan en kısa parça uzunluğuna göre sıralanması.

4. Bu parçacık, oluşturacak üçgenin taban kenarı olacak şekilde kesişimlere dikkat ederek yeni bir nokta bulunması (Şekil 5). $\delta_{1}$ değerinin seçimi denklem 3'deki gibidir. 


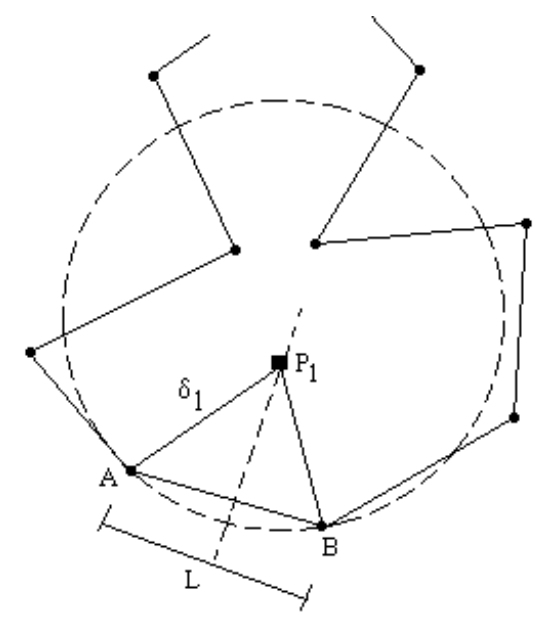

Şekil 5. İlerleyen cephe yönteminde yeni üçgen oluşturulması

$\delta_{1}=\left\{\begin{array}{cc}0.55 * L<1<2 * L & 1 \\ 0.55 * L<1 & 0.55 * L \\ 1>2 * L & 2 * L\end{array}\right.$

5. Bu noktanın listeye eklenmesi.

6. Gereksiz olan dügümlerin listeden çıkarılması ve alan içi tamamen bitinceye kadar çözüm ağı üretimine devam edilmesi şeklinde verilebilir. Şekil 6' da ilerleyen cephe yöntemi adımları verilmiştir [10].
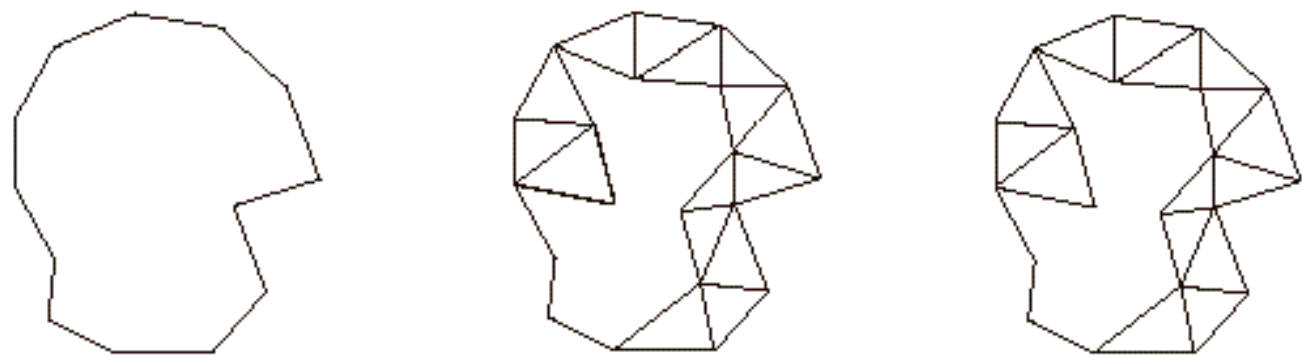

Şekil 6. İlerleyen cephe yönteminde yeni düğg̈m eklenmesi işlemi

Yeni düğüm eklenmesinin gerekmediği durumlar da, ilerleyen cephe yöntemi diagonal olarak düğümlerin birleştirilmesi şeklinde çalışır. Şekil 7' de diagonal olarak düğümlerin birleşimi görülmektedir. 

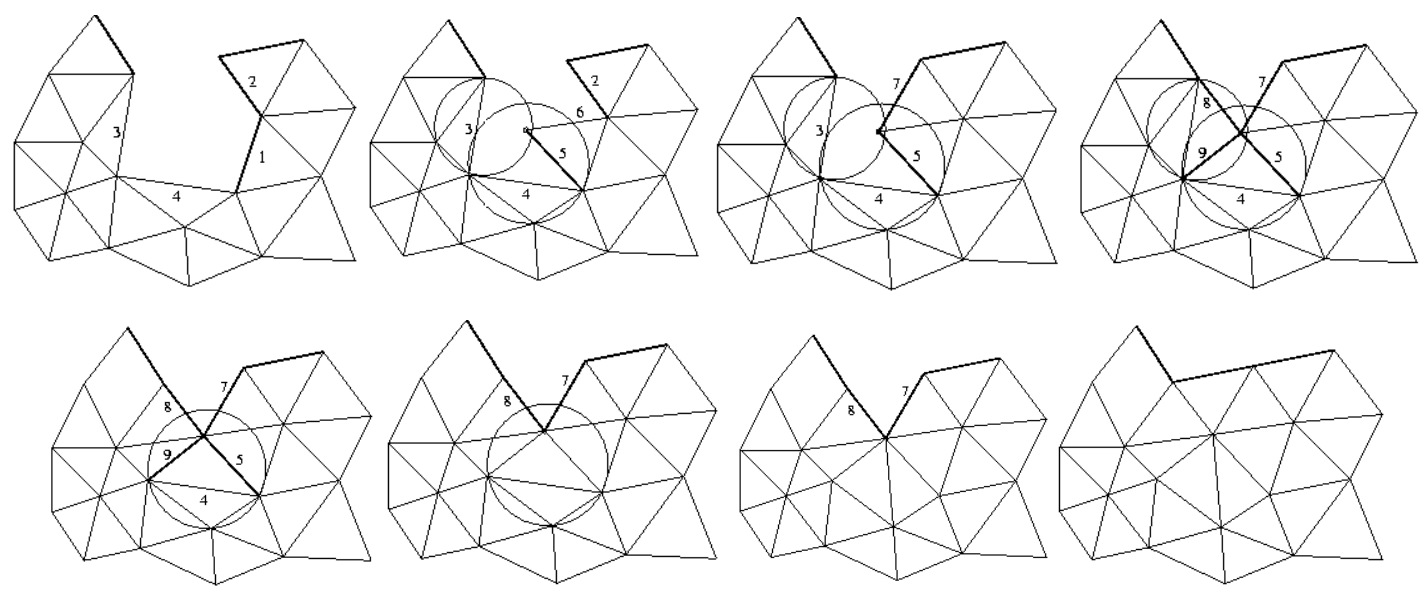

Şekil 7. Diagonal olarak düğümlerin birleştirilmesi

Şekil 8'de ilerleyen cephe yöntemi ile elde edilmiş çözüm ağı örnekleri görülmektedir [11].
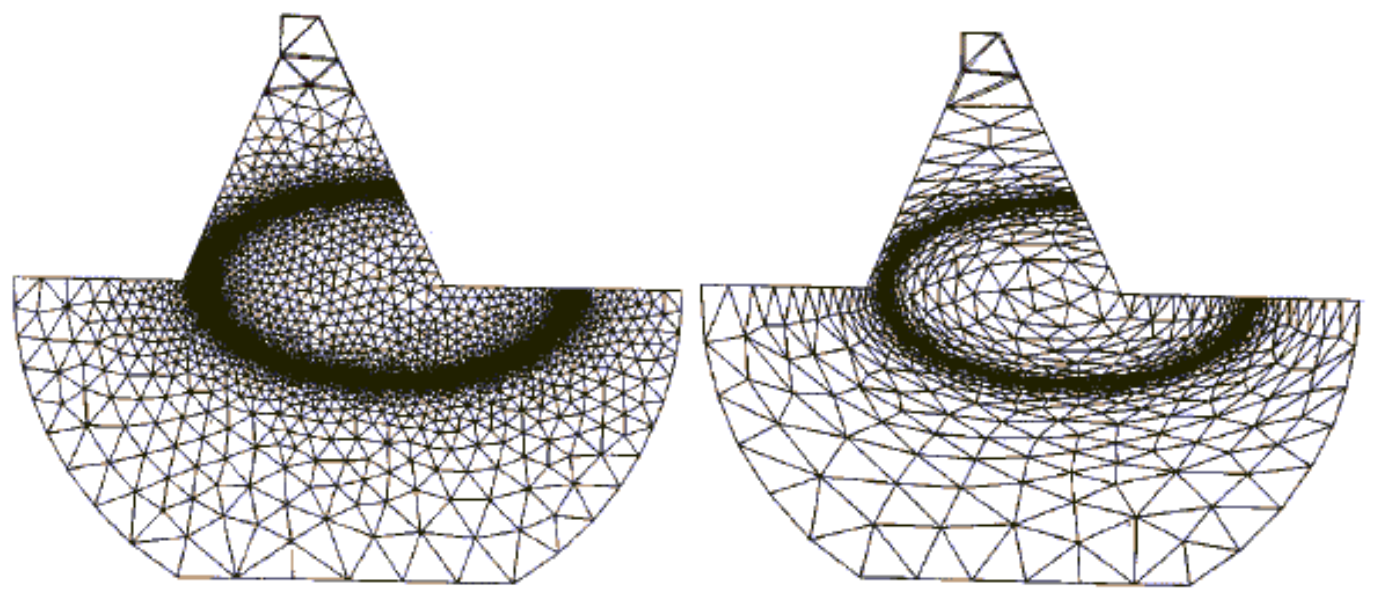

Şekil 2.8. İlerleyen cephe yöntemi ile üretilmiş iki boyutlu çözüm ağı örnekleri

\subsubsection{Yörünge Çizgiler Kullanarak Çözüm Ă̆ı Üretimi}

Yörünge çizgiler (contour) kullanarak çözüm ağı üretimi ilk olarak değişken boyutlu elemanlara sahip çözüm ağı üretiminde kullanılmıştır. Uygun şekilde hesaplanmış düğüm dağılım fonksiyonunu belirleyen yörünge çizgileri, alt bölgeler içinde problem domeninin bölmelenmesini sağlamaktadır. Özellikle değişken boyutlu sonlu eleman üreteçleri, ancak genel amaçlı sonlu eleman üreteçleri ile mümkün olmaktadır. Şekil 9 bu yöntem ile üretilmiş çözüm ağı örneklerini göstermektedir [12].
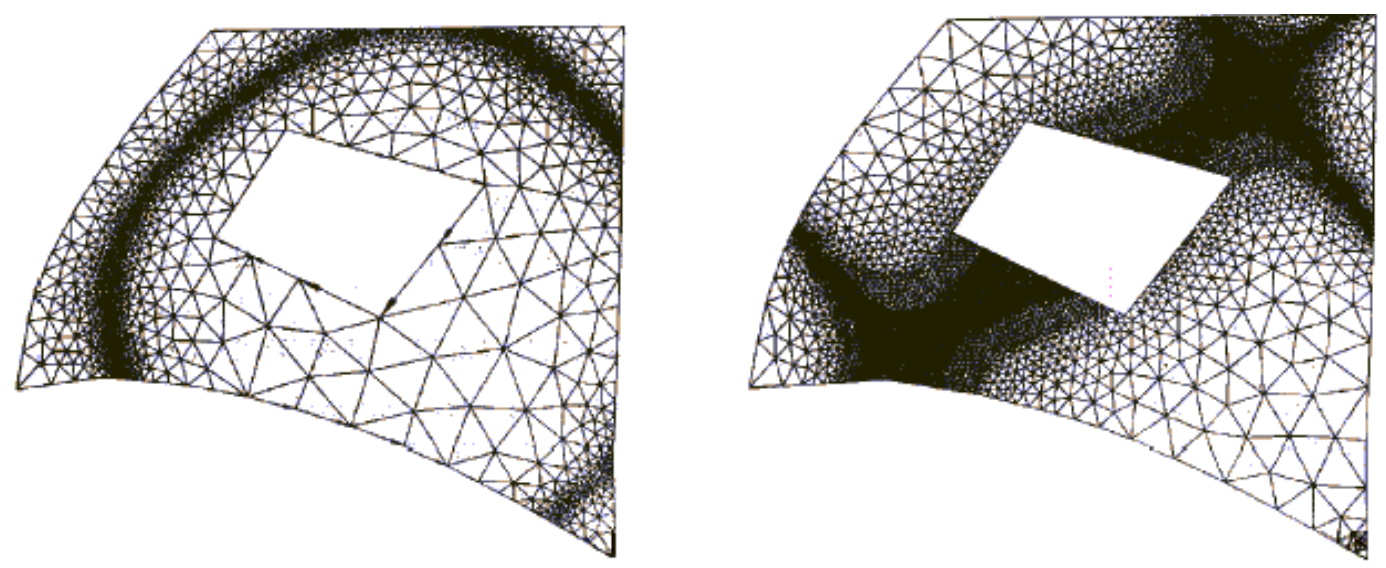

Şekil 9. Yörünge çizgi yöntemi ile üretilmiş olan çözüm ağı örnekleri 


\subsubsection{Alt bölmeleme Yoluyla Kenar Bölme Tekniği}

Bu teknikte yapılan, başlangıçta çözüm ağı üretilecek alana ait kaba bölmelemenin elle veya otomatik bölme yapan bir program ile kabaca bölmelenmesi ve daha sonra bu alanların daha küçük bölmelemelere ayrıştırılmasıdır. Bu işlem bilgisayarlı grafikte alt bölmeleme (subdivision) olarak bilinir [13]. Altbölmelemenin yapılabilmesi için gerekli şart önceden bir bölmelemenin gerekmesidir. Şekil 10' da altbölmeleme tekniğinin uygulandığı basit dikdörtgensel bir yapı görülmektedir.
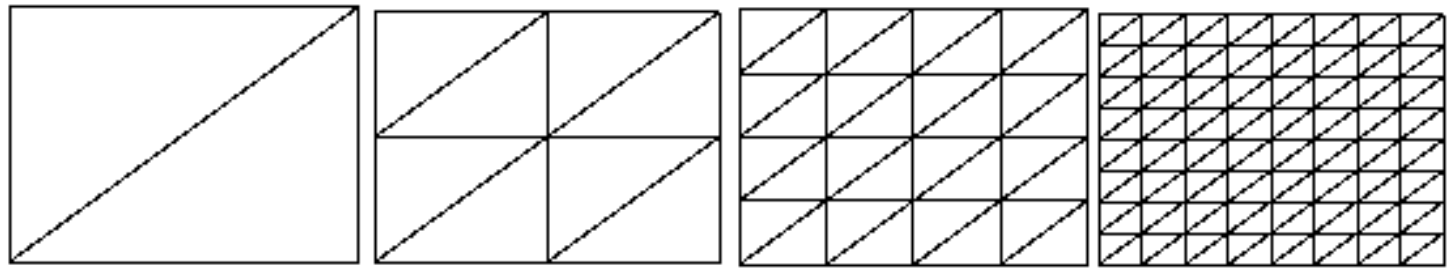

Şekil 10. İkili altbölmeleme tekniği en soldaki şekil orijinal başlangıç çözüm ağı ve diğerleri alt bölmelenmiş şekiller

Yapılan işlem her bir kenar iki eşit parçaya bölmek ve bir üçgenden dört üçgen elde etmektir. Bu yöntem ikili alt bölmeleme olarak adlandırılır. Bu yöntemin avantajı nesne sinırlarına ait bütünlüğün korunabiliyor olmasıdır. Bu şekilde çözüm ağının tümü üzerinde istenildiği kadar bölmeleme yapılması sağlanmış olacaktır. Yöntem hem bölgesel hem de genel anlamda kontrolü sağlayabilme yeteneğine sahiptir. Şekil 11' de bölgesel olarak daha fazla çözüm ağı üretilmiş şekil görülmektedir.

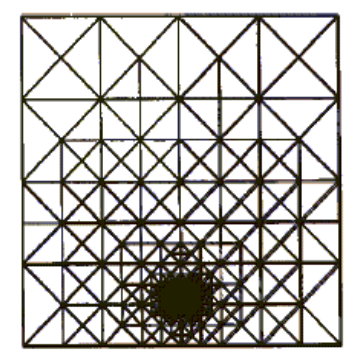

Şekil 11. Altbölmeleme tekniği ile üretilmiş bölgesel kontrollü çözüm ağ1

\section{2. İki Boyutlu Dörtgensel Çözüm Ağları}

Haritalama (mapping) yöntemi ve çekme yöntemi ile dörtgensel çözüm ağı üretimi teknikleri en yaygın kullanılan çözüm ağı üretim teknikleridir [14] . Bu yöntemin genel özelliği sadece yapısal çözüm ağlarının üretilebilmesidir. Ancak eleman boyutlarındaki değişikliklerle yapısal olmayan çözüm ağları dolaylı yoldan üretilebilmektedir. Yapısal olmayan dörtgensel çözüm ağı üretim teknikleri iki ana gruba ayrılır; Bunlar doğrudan yöntemler ve dolaylı yöntemlerdir.

\subsubsection{Doğrudan Yöntemler}

Doğrudan yöntemleri iki ana gruba ayırmak mümkündür. Birincisi; verilen problem ortamının basit bölgelere ayrıştırılmasıdır. Diğeri ise düğümlerin ve elemanlarının yerinin ilerleyen cephe yöntemine benzer şekilde üretilebilmesidir. Dörtgen ağacı yöntemi ile dörtgensel çözüm ağı üretim tekniği birinci gruba girmektedir. İki boyutlu uzayda başlangıç bölmelemesi yapıldıktan sonra sınırlarda bütünlük sağlanıncaya kadar alt bölmeleme işlemi yapılır. Talbert tarafından alt bölmeleme işleminde öz yinelemeli algoritmayı kullanan bir yöntem verilmiştir. Zhu [9] tarafından ilerleyen cephe yöntemi yardımıyla sınırlardan başlayarak dörtgenler oluşturma üzerinde durulmuştur.

\subsubsection{Dolaylı Yöntemler}

Dolaylı yöntemlerin esası, çözüm ağı üretilecek alanın ilk olarak üçgenlere ayrıştırılması daha sonra üçgenler birleştirilerek veya bölerek dörtgensel yapılar oluşturulmasıdır. Şekil 12 bu şekilde üretilmiş dörtgensel bir çözüm ağını göstermektedir. 

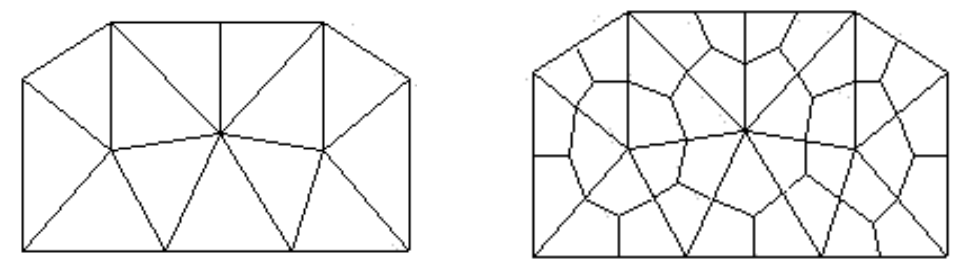

a)

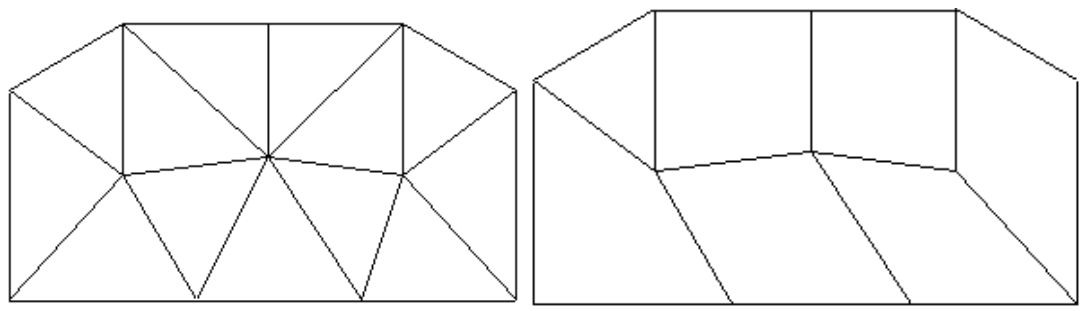

b)

Şekil 12. Dolaylı bir şekilde dörtgensel çözüm ağı üretimi a)Bir üçgenden üç dörtgenin oluşturulması b)İki üçgenin birleştirilip bir dörtgen oluşturulması

\section{Hareketli Çözüm A $\breve{g}$ Üretimi}

Kısmi diferansiyel denklemlerin çözümü için birçok sayısal yöntem geliştirilmiştir ve bu yöntemlerin her birinin kendine göre avantajları ve dezavantajları vardır. Bu nümerik yöntemler problem tipi hakkındaki bilgiler kullanılarak seçilir. Özellikle, hareketli cepheler ve darbeler içeren kütlenin korunumu kanunu gibi lineer olmayan problemlerin çözümünde bu nümerik yöntemler kullanılır. $\mathrm{Bu}$ tip problemlerde bazı bölgelerdeki çözüm yüksek çözünürlüğe sahip olabilmekte; bazı bölgelerde ise daha az çözünürlüğe sahip olmaktadır. İhtiyaç duyulan bu çözünülürlük düğüm sayılarının arttırılması veya uyarlamalı yöntemler kullanılarak elde edilebilir. Böylece çözümün hızla değiştiği bölgelerdeki düğüm sayısı arttırılarak çözümün daha hızlı ve doğru yapılması sağlanır. Geliştirdiğimiz programda çözümün hızla değiştiği bölgeler daha fazla sayıda üçgen elemana bölünerek sonlu elemanlar analizinin daha hızlı ve doğru sonuca ulaşması sağlanabilmektedir. Aşağıda geliştirdiğimiz programın akış şeması ve örnek uygulamalar görülmektedir. 


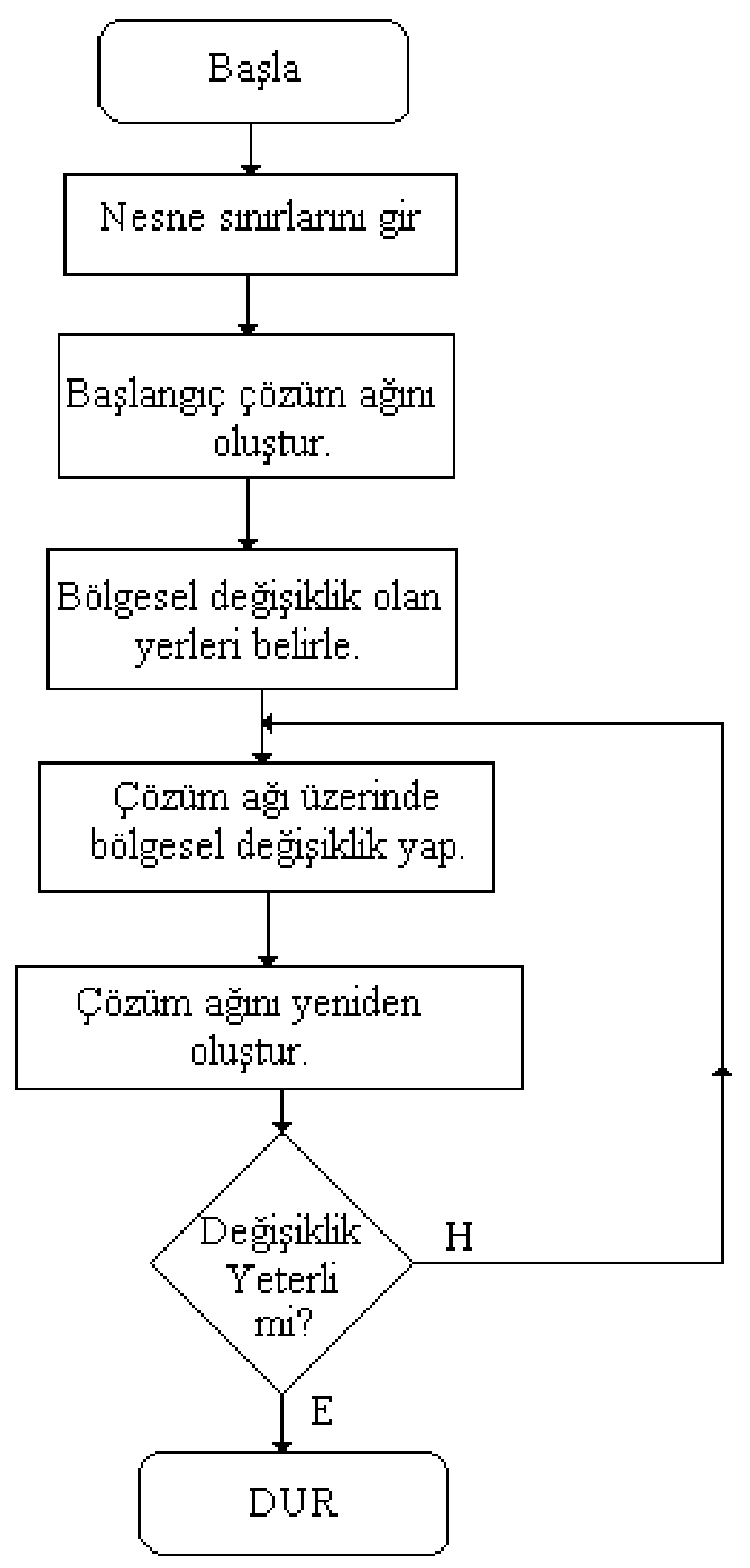

Şekil 13. Geliştirilen programın akış diyagramı

Şekil 14'de geliştirilen program yardımıyla elde edilmiş çözüm ağı üzerinde sinüs bir çizgi boyunca değişim görülmektedir. Burada kullanılan grid sayısı 841 dörtgen ve 1682 üçgen eleman vardır. Burada $y=\sin (x)$ denkleminin belli bir kalınlıktaki kısmının etrafındaki değişim gösterilmiştir. 

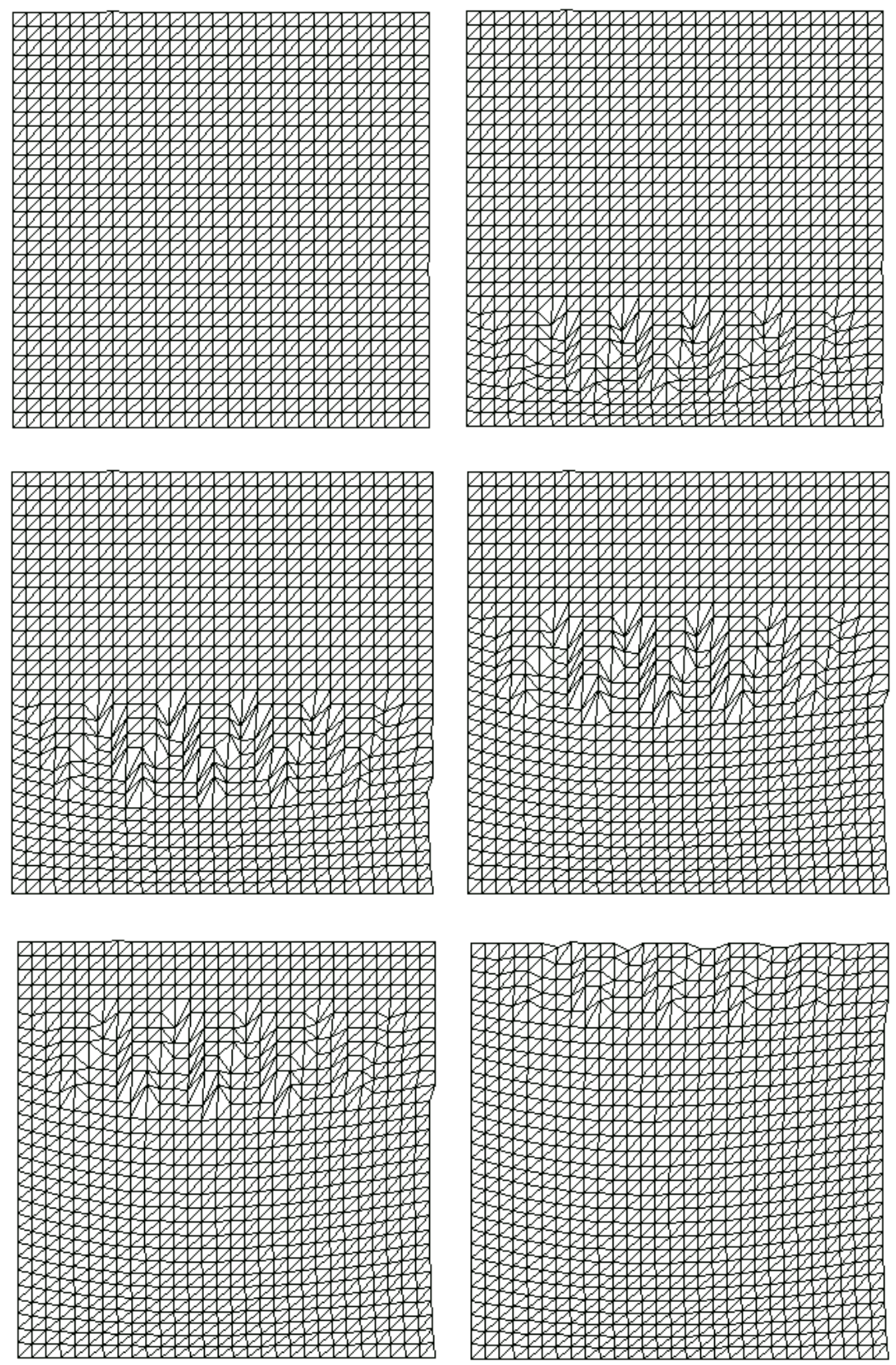

Şekil 14. Üretilen çözüm ağı üzerinde sinüs bir çizgi boyunca değişim

Şekil 15'de geliştirilen program yardımıyla elde edilmiş çözüm ağı üzerinde dikdörtgensel bir bölgedeki değişim görülmektedir. Burada kullanılan grid sayıs1 841 dörtgen ve 1682 üçgen eleman vardır. 

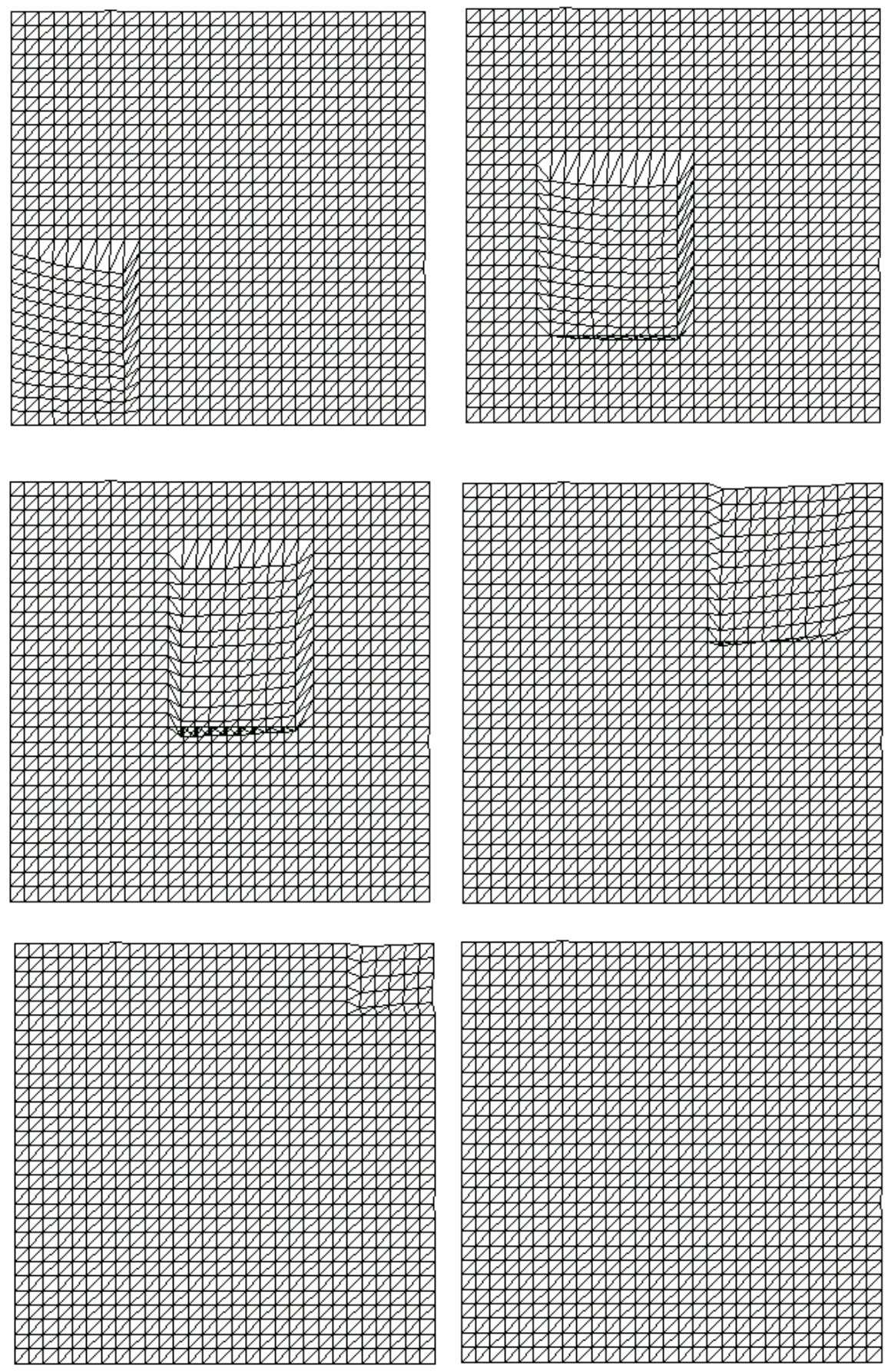

Şekil 15. Üretilen çözüm ağı üzerinde dikdörtgensel değişim

Şekil 16'da geliștirilen program yardımıyla elde edilmiş çözüm ağı üzerinde dairesel bir bölgedeki değişim görülmektedir. Burada kullanılan grid sayısı 841 dörtgen ve 1682 üçgen eleman vardır. 

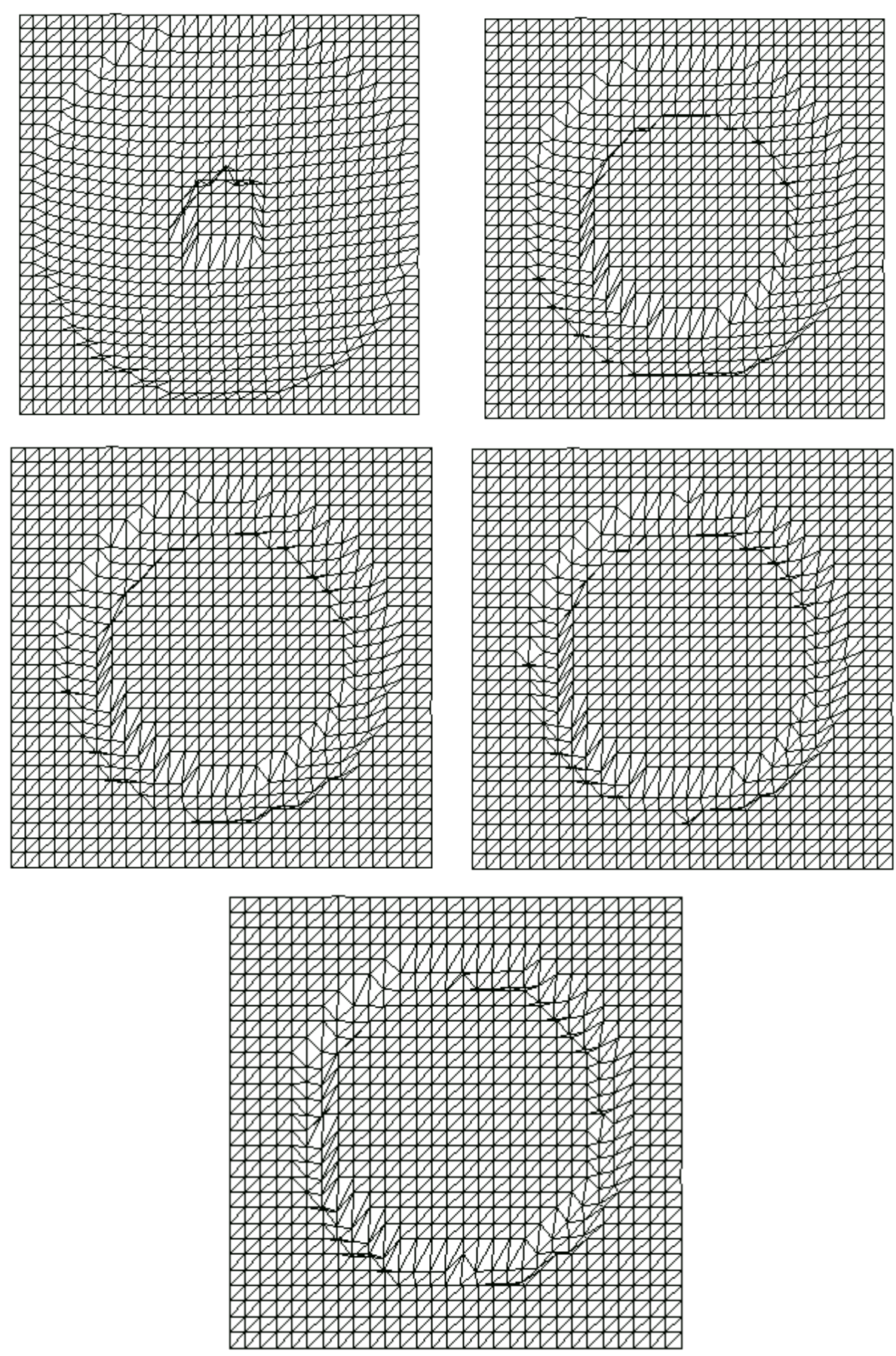

Şekil 16. Üretilen çözüm ağı üzerinde dairesel değişsim

\section{Sonuç}

Bu çalışmada çözüm ağı üretim yöntemlerinden bahsedilerek geliştirilen program yardımıyla hareketli çözüm ağı üretim örnekleri verilmiştir. Bu sayede diferansiyel denklemin hızlı değiştiği bölgedeki eleman sayısı artırılarak daha doğru ve hızlı çözüme ulaşılabilmektedir. Özellikle elektrik makinalarının sonlu elemanlar analizi yapılırken elektrik alan şiddetinin, magnetik akının hızla değiştiği bölgelerde hareketli çözüm ağı elde edilerek sonlu elemanlar analizi yapılırsa daha doğru ve hızlı sonuçlar elde edilecektir.

Bundan sonraki çalışmalarda geliştirilen program yardımıyla zaman bağımlı olarak değişen bir diferansiyel denklemin hareketli çözüm ağı üretilerek sonul elemanlar analizi yapılabilir ve klasik sonlu elemanlar analizi ile bulunan sonuçlar karşılaştırılabilir. 


\section{Kaynaklar}

1. Aydın M., Kuryel B., Gündüz G., Oturanç G. 2001. Diferansiyel Denklemler ve Uygulamaları, Barış Yayınları Fakülteler Kitabevi, İzmir.

2. Rannacher R. 2001. Adaptive Galerkin Finite Element Methods for Partial Differential Equations, Journal of Computational and Applied Mathematics, 128: 205-233.

3. Brenner S. 2002. The Mathematical Theory of Finite Element Method, Springer Verlag Press, Berlin.

4. Hughes T.R. 2000. The Finite Element Method Linear Static and Dynamic Finite Element Method, Dover Publications, New York.

5. Lo S.H. 2002. Finite Element Mesh Generation and Adaptive Meshing, Prog. Struct. Analysis Materials, 4: 381-399.

6. Delaunay B. 1934. Sur la Sphere Vide, Bulletin de l'Académie des Sciences de l'URSS, 1934: 793-800.

7. Lawson C.L. 1977. Software for C1 Surface Interpolation, Mathematical Software III 161-194, Academic Press, San Diego.

8. Baker T.J. 1989. Automatic Mesh Generation for Complex Three-dimensional Regions Using a Constrained Delaunay Triangulation, Engineering with Computers, 5: 161-175.

9. Zhu J.Z., Zienkiewicz O.C., Hinton E., Wu J. 1991. A New Approach to The Development of Automatic Quadrilateral Mesh Generation, International Journal for Numerical Methods in Engineering, 32: 849-866.

10. Lee C.K. 2000. Automatic Metric Advancing Front Triangulation Over Curved Surfaces, Engineering Computations, 17 (1): 48-74.

11. Lo S.H. 1991. Automatic Mesh Generation and Adaptation by Using Contours, International Journal for Numerical Methods in Engineering, 31: 689-707.

12. Shephard M.S., Georges M.K. 1991. Automatic Three-dimensional Mesh Generation by the Finite Octree Technique, International Journal for Numerical Methods in Engineering, 32: 709749.

13. Vello L., Zorin D. 2001. 4-8 Subdivision, Computer Aided Geometric Design, 18: 397-427.

14. Zienkiewicz O.C., Phillips D.V. 1971. An Automatic Mesh Generation Scheme for Plane and Curved Surfaces Isoparametric Coordinates, International Journal for Numerical Methods in Engineering, 3: 519-528. 